\title{
Emerging Concern from Short-Term Textile Leaching: A Preliminary Ecotoxicological Survey
}

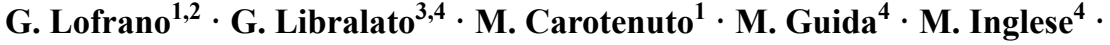 \\ A. Siciliano ${ }^{4} \cdot$ S. Meriç 5
}

Received: 20 April 2016 / Accepted: 27 September 2016 / Published online: 4 October 2016

(C) Springer Science+Business Media New York 2016

\begin{abstract}
Textile dyes and their residues gained growing attention worldwide. Textile industry is a strong water consumer potentially releasing xenobiotics from washing and rinsing procedures during finishing processes. On a decentralised basis, also final consumers generate textile waste streams. Thus, a procedure simulating home washing with tap water screened cotton textiles leachates $(n=28)$ considering physico-chemical $\left(\mathrm{COD}, \mathrm{BOD}_{5}\right.$, and $\mathrm{UV}$ absorbance) and ecotoxicological data (Daphnia magna, Pseudokirchneriella subcapitata and Lepidium sativum). Results evidenced that: (i) leachates presented low biodegradability levels; (ii) toxicity in more than half leachates presented slight acute or acute effects; (iii) the remaining leachates presented "no effect" suggesting the use of green dyes/additives, and/or well established finishing processes; (iv) no specific correlations were found between traditional physico-chemical and ecotoxicological data.
\end{abstract}

G. Libralato

giovanni.libralato@unive.it

1 Department of Chemistry and Biology, University of Salerno, via Giovanni Paolo II 132, Fisciano, 84084 Salerno, Italy

2 Department of Environmental and Civil Engineering, University of Napoli "Federico II", Via Claudio 21, 80125 Naples, Italy

3 Department of Environmental Sciences, Informatics and Statistics, University Cà Foscari Venice, Via Torino 155, 30172 Venice-Mestre, Italy

4 Department of Biology, University of Naples Federico II, Complesso Universitario di Monte S. Angelo, Via Cinthia ed. 7, 80126 Naples, Italy

5 Çorlu Engineering Faculty, Environmental Engineering Department, Namik Kemal University, Çorlu 59860, Tekirdağ, Turkey
Further investigations will be necessary to identify textile residues, and their potential interactions with simulated human sweat in order to evidence potential adverse effects on human health.

Keywords Dye $\cdot$ Textile $\cdot$ Cotton $\cdot$ Leachate Ecotoxicity

Contaminants are considered as "emerging" if they have not been historically present in the environment on a global scale, even because nobody looked at them intentionally. They can be commonly derived from both treated and untreated wastewater indicating that they are mostly produced at industrial scale, currently used also in everyday homecare activities, and easily and unintentionally dispersed into the environment. Some recent examples are pharmaceutical and personal care products (Carotenuto et al. 2014; Lofrano et al. 2016), engineered nanomaterials (Libralato 2014), tannins (Lofrano et al. 2008a; Libralato et al. 2011), micro- and nano-plastics (Mattsson et al. 2015). Despite their continuous release worldwide, dyes and their residues on sold textile goods still remain a great problem and their impact has been scarcely evaluated. Consumers involuntarily leach chemicals from textiles during normal wear (e.g. sweat) and washing (e.g. hand washing or washing machine). This risk increases when finishing steps are not applied properly especially in developing countries (Khatri et al. 2015; OEKO 2016). Thus part of chemicals used for textile production could be still present in textile goods and their characterization and proper management is becoming a challenging responsibility for textile manufacturers. Water use from public water supply ranged within 72-400 L per person day $^{-1}$ in EU (EUROSTAT 2016) and $300-380 \mathrm{~L}^{2}$ per person $\mathrm{day}^{-1}$ in USA (USGS 2016). 
At present, many developing countries such as Indonesia (Kerstens et al. 2016), Pakistan (Ensink et al. 2004), Ghana (Keraita and Drechsel 2004), and Senegal (Faruqui et al. 2004) (i.e. estimated consumption of up to $20 \mathrm{~L}_{\text {person day }}{ }^{-1}$ in Africa (IWfA 2016)) struggle to provide water and wastewater services, while textile residues are discharged without any treatment into surface water (Lofrano et al. 2008b). In India, millions of people wash their clothes directly into rivers turning them into giant launderettes (Robinson 2015). In Europe, about $80 \%$ of the population is connected to wastewater treatment, whereas in the South-East Europe (e.g. Turkey, Bulgaria and Romania) only approximately $40 \%$; the remaining part of untreated wastewater flows into the closest receiving water bodies (EEA 2012).

Several studies demonstrated the toxicity of textile dyes (Bae and Freeman 2007; Ballesteros et al. 2006; Bertanza et al. 2013; Bazin et al. 2012; De Souza et al. 2007; Loos et al. 2007; Meriç et al. 2005; Novotny et al. 2006; Srivastava et al. 2004; Suryavathi et al. 2005; Wang et al. 2002) showing potential adverse effects on human health and the environment (Dave and Aspegren 2010). High molecular synthetic textile auxiliaries and dyes can produce wastewater containing large amounts of refractory COD. Respirometric measurements showed that dye carriers could exert high toxicity causing serious inhibition of microbial respirometric activity (Alaton et al. 2006).

This study aimed at evaluating cotton textile leachates in home washing simulated conditions integrating toxicity data (Daphnia magna, Pseudokirchneriella subcapitata, and Lepidium sativum) with basic wastewater information $\left(\mathrm{BOD}_{5}, \mathrm{COD}, \mathrm{UV}-\mathrm{VIS}\right.$ absorbance) in order to provide a preliminary overview of their effects.

\section{Materials and Methods}

Colored cotton textile goods $(n=28)$ were randomly purchased at different prices in Avellino-Salerno area (Italy). All textiles, colored by staining (i.e. no patterned pictures on them), were new and unwashed when purchased. Leachates were produced immersing textiles $\left(1 \mathrm{~m}^{2}\right)$ in $2.5 \mathrm{~L}$ of cold tap water from Salerno aqueduct $\left(100 \mathrm{mg} \mathrm{CaCO}_{3} / \mathrm{L}\right.$, $\mathrm{pH}=7.50, \mathrm{Cl}<0.5 \mathrm{mg} / \mathrm{L})$ at $25^{\circ} \mathrm{C}$ for $30 \mathrm{~min}$ in static conditions (i.e. 1 textile in $2.5 \mathrm{~L}$ in 1 replicate) using a surfaceto-volume ratio $(\mathrm{s} / \mathrm{v})$ of 0.4 similarly to Dave and Aspegren (2010) (i.e. the maximum $\mathrm{s} / \mathrm{v}$ ). Neither soap nor other detergents were used to observe background effects avoiding any washing product potential interference to the final wash out quality. Leachates were stored in $0.5 \mathrm{~L}$ glass bottles (no air space between the sample and the lid) and kept refrigerated at $4{ }^{\circ} \mathrm{C}$. Samples were labeled as summarized in Table 1 . Total chemical oxygen demand (COD) was determined according to APHA (1998). The biological oxygen demand after 5 days $\left(\mathrm{BOD}_{5}\right)$ was measured by manometric pressure difference (OxiTop, ISCO, IT) and after seeding activated sludge taken from a municipal wastewater treatment plant. The $\mathrm{BOD}_{5} / \mathrm{COD}$ ratio identified leachate biodegradability (Chamarro et al. 2001) making leachates with values $>0.4$ suitable for biological treatment (Loos et al. 2007). Absorbance at 254 and $280 \mathrm{~nm}$ was determined in triplicate using UV-VIS spectrophotometer ( $1 \mathrm{~cm}$ quartz tube, Lambda 12 Model, Perkin Elmer, Waltham, Massachusetts), quantifying double bonds and aromatic structures. A battery of toxicity tests was considered including the $72 \mathrm{~h}$ chronic test with $P$. subcapitata, the $24 \mathrm{~h}$ mortality test with $D$. magna, and the $72 \mathrm{~h}$ acute test with L. sativum (Libralato et al. 2016a, b; Lofrano et al. 2016). Before toxicity testing, $\mathrm{pH}$ values were measured (perpHecT LogR meter, model 330, Orion, Beverly, MA, USA) and reported in Table 1. Acute toxicity tests with D. magna were carried out according to ISO (2013). Newborn daphnids $(<24 \mathrm{~h}$ old, $\mathrm{n}=5)$ were exposed in four replicates for 24 and $48 \mathrm{~h}$ at $20 \pm 1{ }^{\circ} \mathrm{C}$ under continuous illumination (1000 lx). Before starting the test, they were fed with P. subcapitata $(300,000$ cells/ $\mathrm{mL}$ ) ad libitum. Toxicity was expressed as percentage of dead organisms. The chronic growth inhibition test with P. subcapitata was carried out according to ISO (2012). Cultures were kept in Erlenmeyer flasks. The initial inoculum contained $10^{4}$ cells $/ \mathrm{mL}$. The specific growth inhibition rate was calculated considering 6 replicates exposed at $20 \pm 1^{\circ} \mathrm{C}$ for $72 \mathrm{~h}$ under continuous illumination $(6000 \mathrm{~lx})$. Effect data were expressed as percentage of growth inhibition. The acute bioassay with $L$. sativum evaluated the potential toxicity considering the root elongation according to OECD (2006). Experiments were conducted in triplicate $(\mathrm{n}=10)$ at $25 \pm 1^{\circ} \mathrm{C}$ for $72 \mathrm{~h}$ in aqueous solutions. Seed germination and root elongation inhibition normalized on negative control data were expressed as percentage of effect, and the germination index (GI) was calculated as reported in Libralato et al. (2016a). The significance of differences between average effect values of different experimental treatments and controls was assessed by the analysis of variance (ANOVA) considering a significance threshold level always set at $5 \%$. When ANOVA revealed significant differences among treatments, post-hoc tests were carried out with Dunnett's method and Tukey's test. The assessment of macrophyte phytotoxicity endpoints was carried out with ImageJ (Schneider et al. 2012). Whenever possible, toxicity was expressed as EC50 along with 95\% confidence limit values. Otherwise, toxicity was expressed as percentage of effect (PE, \%) or toxic unit (TU). Principal component analysis (PCA) and biplot representation were proposed for data integration and interpretation. Statistical analyses and graphs were carried out using Microsoft ${ }^{\circledR}$ Excel 2013/XLSTATC-Pro (Version 7.2, 2003, Addinsoft, Inc., Brooklyn, NY, USA). Toxicity data were integrated 
Table 1 Physico-chemical characterization of textile leachates

\begin{tabular}{|c|c|c|c|c|c|c|c|}
\hline Samples & Colors & $\mathrm{BOD}_{5}(\mathrm{mg} / \mathrm{L})$ & $\mathrm{COD}(\mathrm{mg} / \mathrm{L})$ & $\mathrm{BOD}_{5} / \mathrm{COD}$ & $\mathrm{UV}_{254}(1 / \mathrm{m})$ & $\mathrm{UV}_{280}(1 / \mathrm{m})$ & $\mathrm{pH}$ \\
\hline TW water & Colorless & 0 & $<5$ & 0 & 0 & 0 & 7.50 \\
\hline $\mathrm{T} 1$ & Red & $<10$ & 29 & - & 0.0513 & 0.0366 & 7.63 \\
\hline $\mathrm{T} 2$ & & 10 & 47 & 0.21 & 0.1569 & 0.0986 & 7.52 \\
\hline $\mathrm{T} 3$ & & $<10$ & 17 & - & 0.0687 & 0.0503 & 7.57 \\
\hline $\mathrm{T} 4$ & White & 12 & 56 & 0.21 & 0.2227 & 0.1766 & 7.61 \\
\hline T5 & & $<10$ & 28 & - & 0.1434 & 0.1202 & 7.49 \\
\hline T6 & & $<10$ & 27 & - & 0.1705 & 0.1482 & 7.53 \\
\hline $\mathrm{T} 7$ & & 10 & 33 & 0.30 & 0.0578 & 0.0465 & 7.59 \\
\hline $\mathrm{T} 8$ & & 13 & 118 & 0.11 & 0.1570 & 0.1360 & 7.99 \\
\hline T9 & & 13 & 35 & 0.37 & 0.0332 & 0.0302 & 7.67 \\
\hline $\mathrm{T} 10$ & Yellow & 15 & 66 & 0.23 & 0.2297 & 0.1815 & 7.63 \\
\hline T11 & & 15 & 147 & 0.10 & 3.2566 & 0.9602 & 7.59 \\
\hline T12 & Fuchsia & $<10$ & 7 & - & 0.0238 & 0.0074 & 7.61 \\
\hline $\mathrm{T} 13$ & & $<10$ & 12 & - & 0.1102 & 0.0800 & 7.60 \\
\hline T14 & & $<10$ & 17 & - & 0.0569 & 0.0481 & 7.62 \\
\hline $\mathrm{T} 15$ & Blue & 10 & 128 & 0.08 & 0.0978 & 0.0794 & 7.63 \\
\hline T16 & & 10 & 76 & 0.13 & 0.2159 & 0.1651 & 7.62 \\
\hline T17 & & $<10$ & 10 & - & 0.0761 & 0.0622 & 7.62 \\
\hline $\mathrm{T} 18$ & & 22 & 73 & 0.30 & 0.1846 & 0.1319 & 7.50 \\
\hline T19 & & 11 & 43 & 0.26 & 0.1686 & 0.1260 & 7.50 \\
\hline $\mathrm{T} 20$ & & 13 & 207 & 0.06 & 0.3967 & 0.3206 & 7.49 \\
\hline $\mathrm{T} 21$ & & 20 & 51 & 0.39 & 0.1077 & 0.0803 & 7.48 \\
\hline $\mathrm{T} 22$ & Cream & 20 & 78 & 0.26 & 0.0945 & 0.0457 & 7.51 \\
\hline $\mathrm{T} 23$ & & $<10$ & 27 & - & 0.2582 & 0.092 & 7.55 \\
\hline $\mathrm{T} 24$ & Black & 18 & 73 & 0.25 & 0.1045 & 0.0722 & 7.56 \\
\hline $\mathrm{T} 25$ & Pink & $<10$ & 10 & - & 0.0643 & 0.0398 & 7.68 \\
\hline T26 & Light-blue & 18 & 43 & 0.40 & 0.2147 & 0.1759 & 7.53 \\
\hline $\mathrm{T} 27$ & Light-green & 10 & 66 & 0.15 & 0.2102 & 0.1608 & 7.52 \\
\hline T28 & Blue-gray & 20 & 79 & 0.25 & 0.0801 & 0.0634 & 7.51 \\
\hline
\end{tabular}

$T W$ tap water

according to Libralato et al. (2010) and Persoone et al. (2003) considering the class weight score system.

\section{Results and Discussion}

Physical and chemical data of textile leachates were reported in Table 1. COD values greatly changed (from 10 to $207 \mathrm{mg} / \mathrm{L}$ ), while $\mathrm{BOD}_{5}$ was $\leq 22 \mathrm{mg} / \mathrm{L}$. COD values increased in the following order: Blue $>$ Yellow $>$ Grey $>$ Cream $>$ Black $>$ White $>$ Red $>$ Light blue $>$ Fuchsia. The highest COD value $(207 \mathrm{mg} / \mathrm{L})$ was associated to a blue textile; however, COD from blue goods fell within 10-207 mg/L. Leachate from Fuchsia textiles (T12-14) showed the lowest COD (Table 1). Leachate biodegradability (Chamarro et al. 2001) was always very low $\left(\mathrm{BOD}_{5} / \mathrm{COD} \leq 0.4\right)$. UV-VIS measurements were higher than tap water and varied in a wide range due to their different chemical structures (Table 1). Although there was a strong correlation (0.947) between $\mathrm{UV}_{254}$ and $\mathrm{UV}_{280}$, a limited correlation was noticed between COD and UV-VIS values $\left(\mathrm{COD} / \mathrm{UV}_{254}\right.$ with $p=0.592$ and $\mathrm{COD} / \mathrm{UV}_{280}$ with $p=0.575, \alpha=0.05)$. The $\mathrm{pH}$ values of leachates did not significantly change compared to the initial leaching tap water (7.50). Toxicity data were summarized in Fig. 1 including D. magna 24 h (Fig. 1a), D. magna 48 h (Fig. 1b), $P$. subcapitata (Fig. 1c), and L. sativum (Fig. 1d) effects. The analysis of toxicity data from Fig. 1a evidenced the presence of two main groups of samples considering a threshold value $\leq 10 \%$ for the effects significantly different from the negative control. Most samples presented effects below the established threshold except for T5, T9, T11, T15, T19, T20 and T25, showing toxicity up to 50\% (T11). After $48 \mathrm{~h}$ exposure (Fig. 1b), the number of samples presenting toxicity effects $\leq 10 \%$ decreased evidencing that contact time plays an important role in toxicity definition. Except 
(a) 100

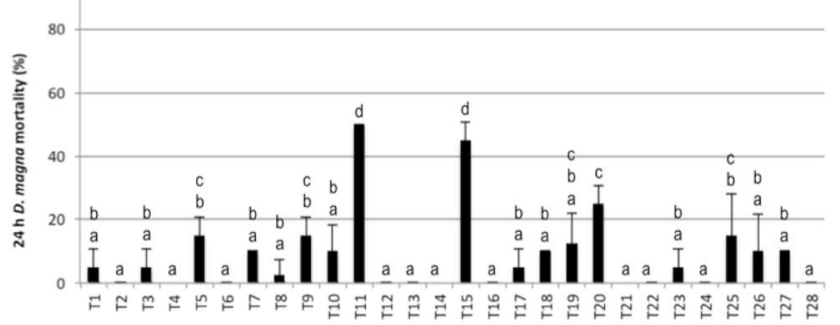

(c) 5

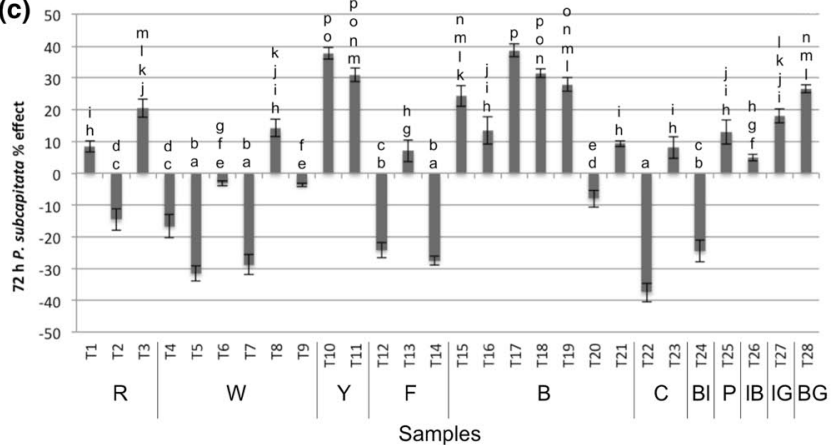

Fig. 1 Textile leachate data (T1-28) with D. magna (24 h) (a), D. magna (48 h) (b), P. subcapitata (72 h) (c), and L. sativum (72 h) (d); data with different letters $(a-n)$ are significantly different (Tukey's,

for 10 samples (T3, T4, T7, T8, T13, T14, T17, T21, T24, and T27), all others presented immobilization effects up to $95 \%$ (T15) in the exposed population. Keeping the same threshold set for D. magna, the effects of leachates on $P$. subcapitata after $72 \mathrm{~h}$ exposure (Fig. 1c) can be clustered into three main groups: (i) no effect $(-10 \% \leq \mathrm{PE} \leq 10 \%)$; (ii) biostimulation growth effect $(\mathrm{PE}<-10 \%)$; (iii) and inhibitory growth effects (PE $>10 \%)$. Only 8 samples (T1, T6, T9, T13, T20, T21, T23, and T26) presented no effect at all. Comparing D. magna $48 \mathrm{~h}$ and microalgae results, only $\mathrm{T} 13$ and T21 were deemed as not toxic. Biostimulation was observed in 8 samples (T2, T4, T5, T7, T12, T14, T22, and T24) up to $-38 \%$. All other leachates presented microalgae growth inhibition effects up to $39 \%$.

According to Libralato et al. (2016a), L. sativum GI (\%) (Fig. 1d) data can be clustered into three main groups: (i) no effect $(80 \% \leq \mathrm{GI} \leq 120 \%)$; (ii) biostimulation (GI $>120 \%$ ); and (iii) inhibition $(\mathrm{GI}<80 \%)$. Several samples presented no effect (T1, T2, T3, T6, T8, T9, T13, T16, T20, T21, T23, T25, T26, T27). Samples T13 and T21 were confirmed to be not toxic also by $L$. sativum. A group of 7 samples (T4, T5, $\mathrm{T} 7, \mathrm{~T} 12, \mathrm{~T} 14, \mathrm{~T} 22$, and T24) showed stimulatory effects up to $136 \%$ of GI and another group of 7 samples (T10, T11, T15, T17, T18, T19, and T28) showed inhibitory effects up to $62 \%$ of GI. Leachate toxicity data from $P$. subcapitata and L. sativum linearly correlated suggesting $(\mathrm{y}=101.214$ $\left.( \pm 0.492)-0.929( \pm 0.020) \mathrm{x} ; \mathrm{R}^{2}=0.986\right)$ that leachates composition acted very similarly in autotrophic photosynthetic organisms. According to Libralato et al. $(2008,2010$,

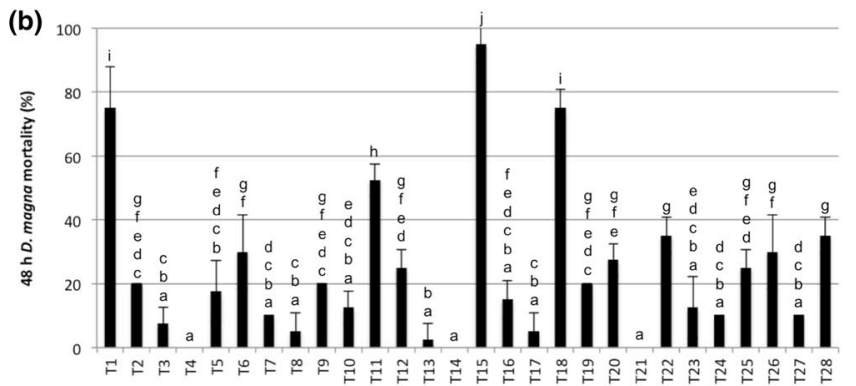

(d)

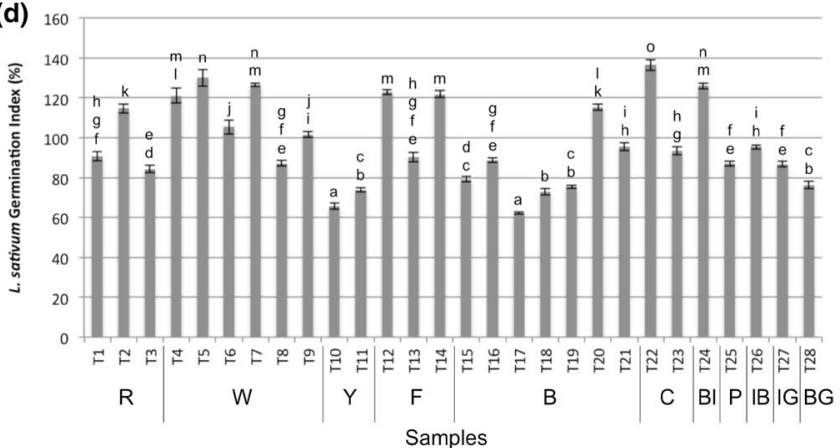

$\mathrm{p}<0.05) ; R$ red, $W$ white, $Y$ yellow, $F$ fuchsia, $B$ blue, $C$ cream, $B l$ black, $P$ pink, $l B$ light-blue, $l G$ light-green, $B G$ blue-gray

2016a, b), toxicity data from a battery of toxicity tests should be integrated providing a final judgment on leachate quality. Considering the class weight score (CWS) system (Persoone et al. 2003), toxicity data (D. magna (48 h), $P$. subcapitata and $L$. sativum) were combined and ranked into three main groups of samples as summarized in Fig. 2: (i) no acute toxicity $(\mathrm{CWS}<0.4)$; (ii) slight acute toxicity $(0.4 \leq \mathrm{CWS}<1)$; and (iii) acute toxicity $(1 \leq \mathrm{CWS}<10)$. The CWS approach confirmed that T13 and T21 presented no acute toxicity because bioassays' results were $\leq 10 \%$. Other samples averagely presented no acute toxicity like T3, T4, T8, T10, T16, T17, T23, T25, T26 and T27. Anyway, their toxicity values taken singly reached a maximum of $20 \%$ effect according to CWS approach. The total amount of no toxic samples accounted for $43 \%$ of the total investigated samples. Approximately $39 \%$ of samples were ranked as slight acute toxic (T1, T2, T5, T6, T7, T9, T14, $\mathrm{T} 19, \mathrm{~T} 20, \mathrm{~T} 24$ and $\mathrm{T} 28)$ and $18 \%$ as acute toxic (T11, T12, $\mathrm{T} 15, \mathrm{~T} 18$, and T22). This means that $57 \%$ of leachates presented effects able to generate some adverse ecotoxicological consequences.

A biplot summarizing PCA results concerning chemical and ecotoxicological data is shown in Fig. 3. The first two principal components accounted for 38.02 and $19.62 \%$ of variation, respectively. Therefore, the two-axis ordination diagram can depict $57.64 \%$ of variation. The biplot regarding component loadings suggested that the F1 scores are influenced by high values of COD, $\mathrm{UV}_{254}$ and $\mathrm{UV}_{280}$ as well as $24 \mathrm{~h} D$. magna toxicity data. The loading of $P$. subcapitata 
Fig. 2 Hazard classification for textile leachates (T1-28) potentially discharged into the aquatic environment according to Persoone et al. (2003); white, no acute toxicity $(\mathrm{TU}<0.4)$; dark gray, slight acute toxicity $(0.4 \leq \mathrm{TU}<1)$; and black, acute toxicity $(1 \leq \mathrm{TU}<10)$; $R$ Red, $W$ White, $Y$ yellow, $F$ fuchsia, $B$ blue, $C$ cream, $B l$ black, $P$ pink, $l B$ light-blue, $l G$ light-green, $B G$ blue-gray

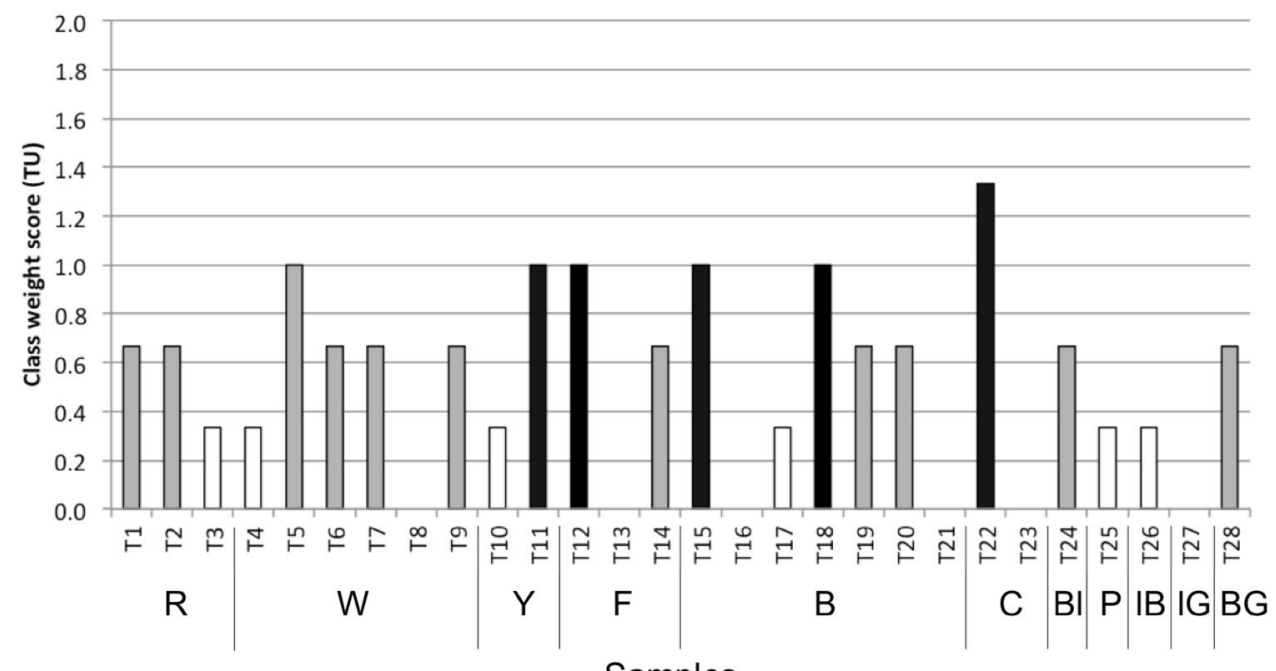

Samples

Fig. 3 Principal component analysis (PCA) as biplot representation with loadings and scores in the coordinates of the first two principal components (F1 and F2) of wastewater samples; Dm_24=D. magna 24 h toxicity data, Dm $48=D$. magna $48 \mathrm{~h}$ toxicity data, Ps $72=P$. subcapitata $72 \mathrm{~h}$ toxicity data; Ls_ $72=L$. sativum $72 \mathrm{~h}$ toxicity data

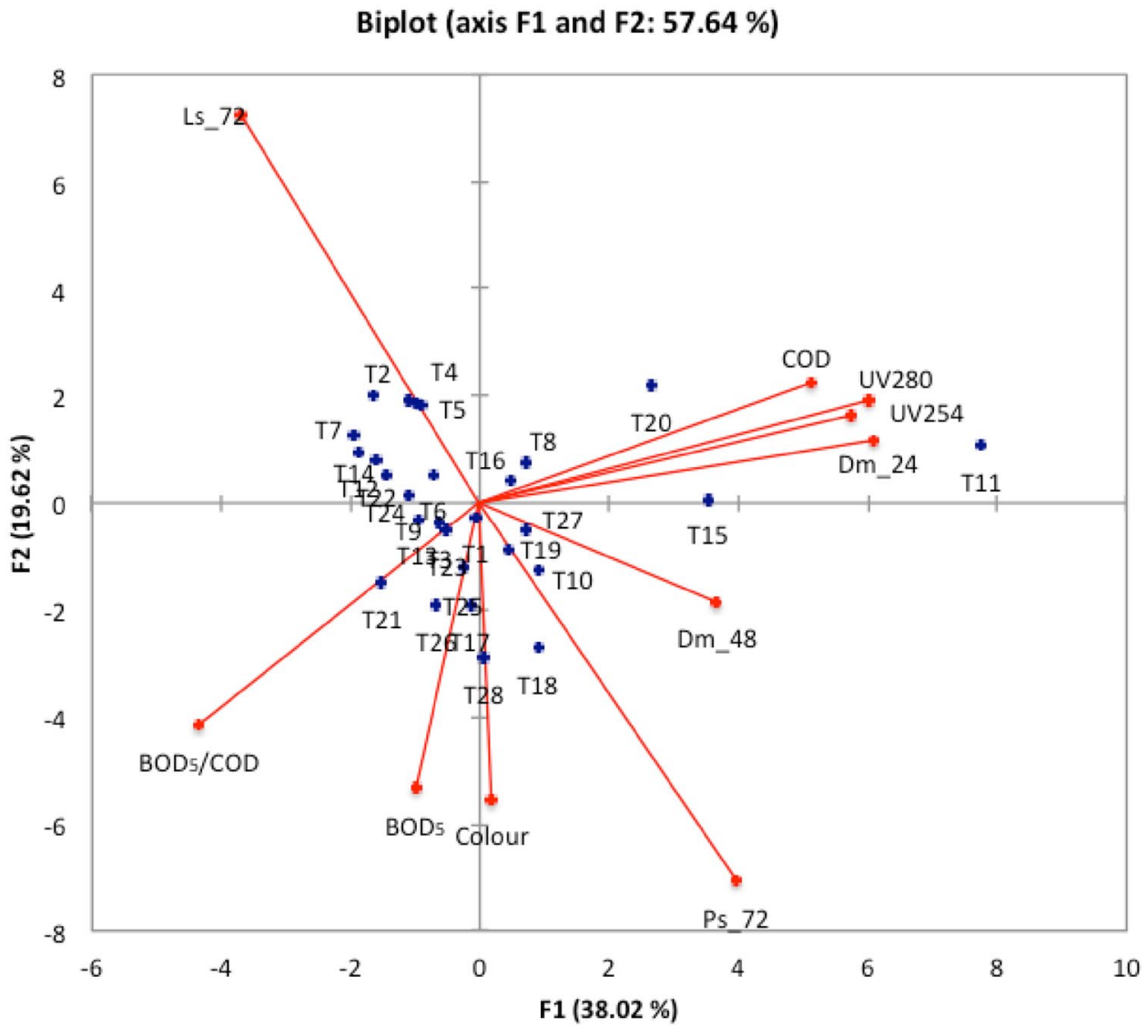

and L. sativum toxicity data mainly influenced F2 scores. Looking at the ordination plot of component scores in F1 and F2 biplot, it was found that wastewater samples could be clustered into two main groups according to eigenvalues: (1) T11, T15 and T20 (F1); and (2) all the remaining. It seems that only T11, T15 and T20 are correlated with $\mathrm{COD}, \mathrm{UV}_{254}$ and $\mathrm{UV}_{280}$ data presenting under an ecotoxicological viewpoint acute (T11 and T15) or slightly acute
(T20) toxicity. The values of $\mathrm{BOD}_{5}, \mathrm{BOD}_{5} / \mathrm{COD}$ and color showed slight/no correlations within the dataset. Dave and Aspegren (2010) reported similar results on textile goods, but considering various fibers other than cotton, identifying significantly higher toxicity for printed rather than unprinted textiles. Textile goods releasing unknown chemicals to the aquatic environment can become a wide emerging concern. This study proposed a survey of potential effects related to 
cotton textile house washing. Results evidenced: (i) chemical residues in tap water leachates related to dyes and dyes' additives presenting a low biodegradability; (ii) toxicity in more than half of the investigated leachates samples presented from slight acute to acute effects; (iii) the remaining part of leachate samples presented no effects according to the selected battery of toxicity tests suggesting the use of green dyes (and/or additives), and/or well established finishing processes; (iv) no specific correlation were found between traditional physico-chemical (COD, $\mathrm{BOD}_{5}, \mathrm{UV}_{254}$, and $U_{280}$ ) and ecotoxicological data. Further studies could investigate which kind of dyes and additives residues are responsible for toxicity effects, identify the best finishing processes enabling low or no toxicity effects in textile leachates normalizing data on textile weft considering the number of fibres per unit area. Moreover, due to the ecotoxicological effects highlighted, it would be interesting assessing the potential interactions between textile residues and simulated human sweat in order to evidence potential adverse effect on human health.

\section{References}

Alaton IA, Insel G, Eremektar G, Babuna FG, Orhon D (2006) Effect of textile auxiliaries on the biodegradation of dyehouse effluent in activated sludge. Chemosphere 62:1549-1557. doi:10.1016/j. chemosphere.2005.06.010

APHA (1998) Standard Methods for the Examination of Water and Wastewater, 20th edn. APHA, AWWA and WEF, Washington

Bae JS, Freeman HS (2007) Aquatic toxicity evaluation of new direct dyes to the Daphnia magna. Dyes Pigm 73:81-85. doi:10.1016/j. dyepig.2005.10.015

Ballesteros O, Zafra A, Navalon A, V'ilchez JL (2006) Sensitive gas chromatographic-mass spectrometric method for the determination of phthalate esters, alkylphenols, bisphenol A and their chlorinated derivatives in wastewater samples. J Chromatog A 1121:154-162. doi:10.1016/j.chroma.2006.04.014

Bazin I, Hassine ABH, Hamouda YH et al (2012) Estrogenic and antiestrogenic activity of 23 commercial textile dyes. Ecotoxicol Environ Saf 85:131-136. doi:10.1016/j.ecoenv.2012.08.003

Bertanza G, Papa M, Pedrazzani R et al (2013) EDCs estrogenicity and genotoxicity reduction in a mixed (domestic + textile) secondary effluent by means of ozonation: a full-scale experience. Sci Total Environ 458-460:160-168. doi:10.1016/j.scitotenv.2013.03.108

Carotenuto M, Lofrano G, Siciliano A et al (2014) $\mathrm{TiO}_{2}$ photocatalystic degradation of caffeine and ecotoxicological assessment of oxidation by products. GNEST J 16(3):265-275

Chamarro E, Marco A, Esplugas S (2001) Use of Fenton reagent to improve organic chemical biodegradability. Wat Res 35:10211047. doi:10.1016/S0043-1354(00)00342-0

Dave G, Aspegren P (2010) Comparative toxicity of leachates from 52 textiles to Daphnia magna. Ecotox Environ Saf 173:629-1632. doi:10.1016/j.ecoenv.2010.06.010

De Souza SMAGU, Forgiarini E, De Souza AAU (2007) Toxicity of textile dyes and their degradation by the enzyme horseradish peroxidase (HRP). J Hazard Mat 147:1073-1078. doi:10.1016/j. jhazmat.2007.06.003

EEA (European Environmental Agency) (2012) Urban wastewater treatment. http://www.eea.europa.eu/
Ensink JH, Mahmood T, van der Hoek W et al (2004) A nationwide assessment of wastewater use in Pakistan: an obscure activity or a vitally important one? Wat Pol 6:197-206

EUROSTAT (2016) http://ec.europa.eu/eurostat/

Faruqui NI, Niang S, Redwood M (2004) 10 Untreated wastewater use in market gardens: a case study of Dakar, Senegal. Wastewater Use Irrigated Agricul 94

ISO (2012) Water quality-freshwater algal growth inhibition test with unicellular green Algae 8692 ISO Geneva

ISO (2013) Water quality: determination of the inhibition of the mobility of Daphnia magna Straus (Cladocera, Crustacea) - acute toxicity test

Iwfa (2016) https://www.water-for-africa.org/en/africa.html. 20th September 2016

Keraita BN, Drechsel P (2004) Agricultural use of untreated urban wastewater in Ghana. Wastewater Use in Irrigated Agriculture: Confronting the Livelihood and Environmental Realities 101-112

Kerstens SM, Spiller M, Leusbrock I, Zeeman G (2016) A new approach to nationwide sanitation planning for developing countries: case study of Indonesia. Sci Tot Environ 550:676-689. doi:10.1016/j.scitotenv.2016.01.104

Khatri A, Peerzada MH, Mohsin M, White M (2015) A review on developments in dyeing cotton fabrics with reactive dyes for reducing effluent pollution. J Clean Prod 87:50-57. doi:10.1016/j. jclepro.2014.09.017

Libralato G (2014) The case of Artemia spp. in nanoecotoxicology. Mar Environ Res 101:38-43. doi:10.1016/j. marenvres.2014.08.002

Libralato G, Volpi Ghirardini A, Avezzù F (2008) Evaporation and air-stripping to assess and reduce ethanolamine toxicity in oily wastewater. J Haz Mat 153:928-936. doi:10.1016/j. jhazmat.2007.09.042

Libralato G, Volpi Ghirardini A, Avezzù F (2010) How toxic is toxic? A proposal for wastewater toxicity hazard assessment. Ecotoxicol Environ Saf 73:1602-1611. doi:10.1016/j.ecoenv.2010.03.007

Libralato G, Avezzù F, Volpi Ghirardini A (2011) Lignin and tannin toxicity to Phaeodactylum tricornutum (Bohlin). J Haz Mat 194:435-439. doi:10.1016/j.jhazmat.2011.07.103

Libralato G, Costa Devoti A, Zanella M et al (2016a) Phytotoxicity of bulk, micro- and nano-sized iron in three plant species. Ecotoxicol Environ Saf 123:81-88. doi:10.1016/j.ecoenv.2015.07.024

Libralato G, Gentile E, Volpi Ghirardini A (2016b) Wastewater effects on Phaeodactylum tricornutum (Bohlin): setting up a classification system. Ecol Indic 60:31-37. doi:10.1016/j.ecolind.2015.06.014

Lofrano G, Aydin E, Russo F et al (2008a) Characterization and fluxes of leather tanning bath chemicals in a large tanning district area, Italy. Wat Air Soil Pollut 8:529-542. doi:10.1007/ s11267-008-9177-7

Lofrano G, Meriç S, Belgiorno V (2008b) Sustainable wastewater management in developing countries: are constructed wetlands a feasible approach for wastewater re-use? Int J Environ Pollut 33:82-92. doi:10.1504/IJEP.2008.018468

Lofrano G, Libralato G, Adinolfi R et al (2016) Photocatalytic degradation of the antibiotic chloramphenicol and its by-products toxicity effects. Ecotoxicol Environ Saf 123:65-71. doi:10.1016/j. ecoenv.2015.07.039

Loos R, Hanke G, Umlauf G, Eisenreich SJ (2007) LC-MS-MS analysis and occurrence of octyl- and nonylphenol. their ethoxylates and their carboxylates in Belgian and Italian textile industry, waste water treatment plant effluents and surface waters. Chemosphere 66:690-699. doi:10.1016/j.chemosphere.2006.07.060

Mattsson K, Hansson LA, Cedervall T (2015) Nano-plastics in the aquatic environment. Environ Sci: Process Imp 17:1712-1721. doi:10.1039/c5em00227c

Meriç S, Selçuk H, Belgiorno V (2005) Acute toxicity removal in textile finishing wastewater by Fenton's oxidation. Ozone and 
coagulation-flocculation processes. Wat Res 39:1147-1153. doi:10.1016/j.watres.2004.12.021

Novotny C, Dias N, Kapanen A et al (2006) Comparative use of bacterial, algal and protozoan tests to study toxicity of azo- and anthraquinone dyes. Chemosphere 63:1436-1442. doi:10.1016/j. chemosphere.2005.10.002

OECD (2006) Guidelines for the testing of chemicals, terrestrial plant test: seedling emergence and seedling growth test

OEKO (2016) Oeko-Tex Standard 100-HOHENSTEIN Product Certification according to Oeko-Tex ${ }^{\circledR}$ Standard 100. Confidence in textiles tested for harmful substances (http://www.hohenstein. deu)

Persoone G, Marsalek B, Blinova I et al (2003) A practical and userfriendly toxicity classification system with microbiotests for natural waters and wastewaters. Environ Toxicol 18:395-402. doi:10.1002/tox.10141

Robinson J (2015) Going to the laundrette-Delhi style: hundreds of men wash clothes in one of the world's most polluted rivers. MailOnline.
Schneider CA, Rasband WS, Eliceiri KW (2012) NIH image to ImageJ: 25 years of image analysis. Nat Methods 9:671-675

Srivastava S, Sinha R, Roy D (2004) Toxicological effects of malachite green. Aquat Toxicol 66:319-329. doi:10.1016/j. aquatox.2003.09.008

Suryavathi V, Sharma S, Sharma S et al (2005) Acute toxicity of textile dye wastewaters (untreated and treated) of Sanganer on male reproductive systems of albino rats and mice. Reprod Toxicol 19:547-556. doi:10.1016/j.reprotox.2004.09.011

USGS (2016) http://water.usgs.gov

Wang C, Yediler A, Lienert D et al (2002) Toxicity evaluation of reactive dyestuff. auxiliaries and selected effluents in textile finishing industry to luminescent bacteria Vibrio fischeri. Chemosphere 46:339-344. doi:10.1016/S0045-6535(01)00086-8 